\title{
An Insight on the Welfare of Working Donkeys in Njoro Community, Nakuru.
}

Grace Atieno', Ngetich Wyckliff', Wahome Margaret Wambui², Chepkirui Evalyne Bett ${ }^{1}$

${ }^{1}$ Department of Veterinary Surgery, Theriogenology and Medicine, Faculty of Veterinary Medicine and Surgery, Egerton

University, Kenya

${ }^{2}$ Department of Public Health, School of Medicine and Health Sciences, Kabarak, Kenya

*Corresponding author: Ngetich Wyckliff, Department of Veterinary Surgery, Theriogenology and Medicine, Faculty of Veterinary Medicine and Surgery, Egerton University. P.O Box 536-20115, Egerton, Kenya

\section{Abstract}

The study focused on assessing donkey welfare awareness among Njoro community. This has been a concern despite legal enforcement since most donkey owners and donkey handlers still mishandle these animals, and they do not recognize them as sentient animals but instead, they are viewed as a bridge for making money. Questionnaires and observational studies were used to collect data. Data collection was to focus on those donkeys with poor welfare status.

A purposive sampling procedure was used to collect data and based on the findings; most of the respondents were married males thus making the business of using the working donkeys as male business. Most respondents (84.1\%) owned 2 donkeys and the donkeys were mostly males. Two-thirds (76. $2 \%$ ) of the working donkeys work 6 days in a week to transport water to hotels, construction sites and homesteads however $79.4 \%$ of the working donkeys work from morning to noon. This means that despite the strenuous work that the donkeys were put through they were given some hours to rest. Even though $95.2 \%$ respondents admitted that they would leave donkeys to graze on their own after working, some (4.8\%) would supplement with 1 to $1 / 2$ suck of feed in the evening after work. A huge percentage (90.5\%) would provide water at least once a day though this was done only on working days. Health wise, $93.7 \%$ of the study donkeys had overgrown hooves with significant percentage having wounds on the shoulders, rump and fetlocks of the forelimbs. All the interviewed respondents were against the donkey slaughter since they claimed that they do not recognized donkey meat as being edible and that the slaughter resulted to too much donkey theft. Therefore, welfare status among working donkeys in the study area is poor which could be attributed to poor management practices.

Keywords:Assessment; Awareness; Donkey owners/users.

\section{Introduction}

For many years, animal welfare has been shown to be an important issue for the general public [1]. Due to this concern, legislative codes of practices, organization and campaigns in institutions have been developed to influence improving the donkey welfare among people [2]. All these laws and organizations fight for the animals to ensure that they are in good state of welfare and to achieve this, they assess the general health of the animal, the comfortability of the animals, the behavior change of the animals, human and animal interaction and the animal population.

Despite the legal enforcement and creation of animal welfare awareness among people, there has been reduction in donkey welfare [3] and therefore more researches and efforts need to be done to facilitate improving the welfare of the donkeys. Today the welfare problems that the donkeys face include inadequate food and water, disease incidences and injuries, harsh environmental conditions and poor managements [4].

Donkey welfare is one of the primary issues that take millions of money from various animal welfare organization to create and improve awareness among the donkey handlers and farmers despite the legal enforcement. This has been due to the alarming increase of the animal neglect and ignorance [4]. The welfare issues are also contributed by the minimal studies and researches done on donkeys thus not many people are aware of the donkey welfare and management [4]. These donkeys' welfare issues need to be focused on and studied to minimize the economic constraints that the developing countries are undergoing to improve the donkey welfare. 
Methodology

The study was conducted in Njoro community which is about 26KM from Nakuru town. Njoro is a ward with a population size of 5,101 donkeys and 238,233 human populations [5]. The region experienced a lot of rainfall (moderate climatic condition) thus their main economic activity was agriculture thus the use of donkeys to transport the agricultural products (iris potatoes, maize, cabbages, carrots and cow peas) to the market and to perform other activities. Other individuals were business oriented thus they used donkeys to perform their businesses.

Purposive sampling procedure was used to obtain data. This was achieved through observation and measuring of the welfare status of the donkeys and administering questionnaires to donkey owners/users. This data was collected at the water points, markets and along the roadsides. These were preferred sites since most donkeys and donkeys owners were on their businesses at these points. A total of 98 donkeys and 63 respondents using a formula describe elsewhere were recruited into this study giving a representative sample size to determine the welfare status of working donkeys. The collected data from the working donkey with poor welfare status was edited, re-written and organized after which it was entered into Microsoft excel spreadsheet for further analysis. Statistical significance was considered at P-value $<0.05$ with 95\% confidence and a $5 \%$ margin of error.

\section{Results}

During this assessment, 63 donkey owners and handlers were interviewed. The interview was based on questionnaires, observational surveys of the donkey based on handling, harnessing, health parameter assessment and management. The findings were therefore summarized in a descriptive analysis and the results discussed broadly as shown below.

\section{Descriptive Analysis}

\section{Demographic Characteristic of Working Donkey Owners/Handlers}

The donkey owners/handlers were virtually male thus making this business of using working donkey to be male business. $93.7 \%$ of the respondents were married and $96.8 \%$ had knowledge on how to interact with the donkeys. This study also revealed that $84.1 \%$ of the respondents owned 2 donkeys, $11.1 \%$ owned more than 2 donkeys and the rest owned 1 or hired donkeys for their activities. This therefore showed that the working donkeys could be used even when they are sick or tired. This is shown in the (Table 1) below.
Table 1: Demographic characteristic of working donkey owners/ handlers.

\begin{tabular}{|c|c|c|c|}
\hline Variables & Respondents & Frequency & Percentage \\
\hline \multirow{2}{*}{ Sex } & Male & 60 & 95.2 \\
\cline { 2 - 4 } & Female & 3 & 4.8 \\
\hline Marital status & Married & 59 & 93.7 \\
\hline \multirow{3}{*}{$\begin{array}{c}\text { Nevel of education } \\
\text { donkeys owned }\end{array}$} & Single & 4 & 6.3 \\
\cline { 2 - 4 } & Literate & 61 & 96.8 \\
\cline { 2 - 4 } & Illiterate & 2 & 3.2 \\
\cline { 2 - 4 } & More than 2 donkeys & 7 & 1.6 \\
\cline { 2 - 4 } & Hired donkeys & 2 & 11.1 \\
\hline
\end{tabular}

\section{Number of Working Days of Donkeys Per Week}

As shown in the data illustrated in the above figure (Figure 1) regarding the number of working days of donkeys per week, $76.2 \%$ of working donkeys work 6 days in a week with Sunday being the resting day.15.9\% worked 7 days while $7.9 \%$ worked 2 days that is Wednesdays and Saturdays during the market days.

\section{Number of Working Hours}

This study also reveals the number of working hours for working donkeys, majority (79.4\%) of working donkeys in this study work from morning to noon as shown in the above (Table 2).

Table 2: Number of working hours.

\begin{tabular}{|c|c|c|}
\hline Number of working hours & Frequency & Percentage (\%) \\
\hline Morning to noon & 50 & 79.4 \\
\hline Noon to evening & 0 & 0 \\
\hline Morning hours & 5 & 7.9 \\
\hline Evening hours & 5 & 7.9 \\
\hline Afternoon & 1 & 1.6 \\
\hline Morning to evening & 2 & 3.2 \\
\hline
\end{tabular}

\section{Feeding}

According to this study, $95.2 \%$ of the owners interviewed admitted that they leave the donkeys to graze on their own on dry grass after work. Besides grazing, 3.2\% and $1.6 \%$ of the interviewed owners provide the donkeys 1 suck and $1 / 2$ suck of dry grass and maize straw respectively in the evening after work as illustrated in the data in the above figure (Figure 2). According to this study, dry grass is the

Citation: Grace Atieno, Ngetich Wyckliff, Wahome Margaret Wambui, Chepkirui Evalyne Bett. An Insight on the Welfare of Working Donkeys in Njoro Community, Nakuru. Op Acc J Bio Sci \& Res 7(1)-2021. 


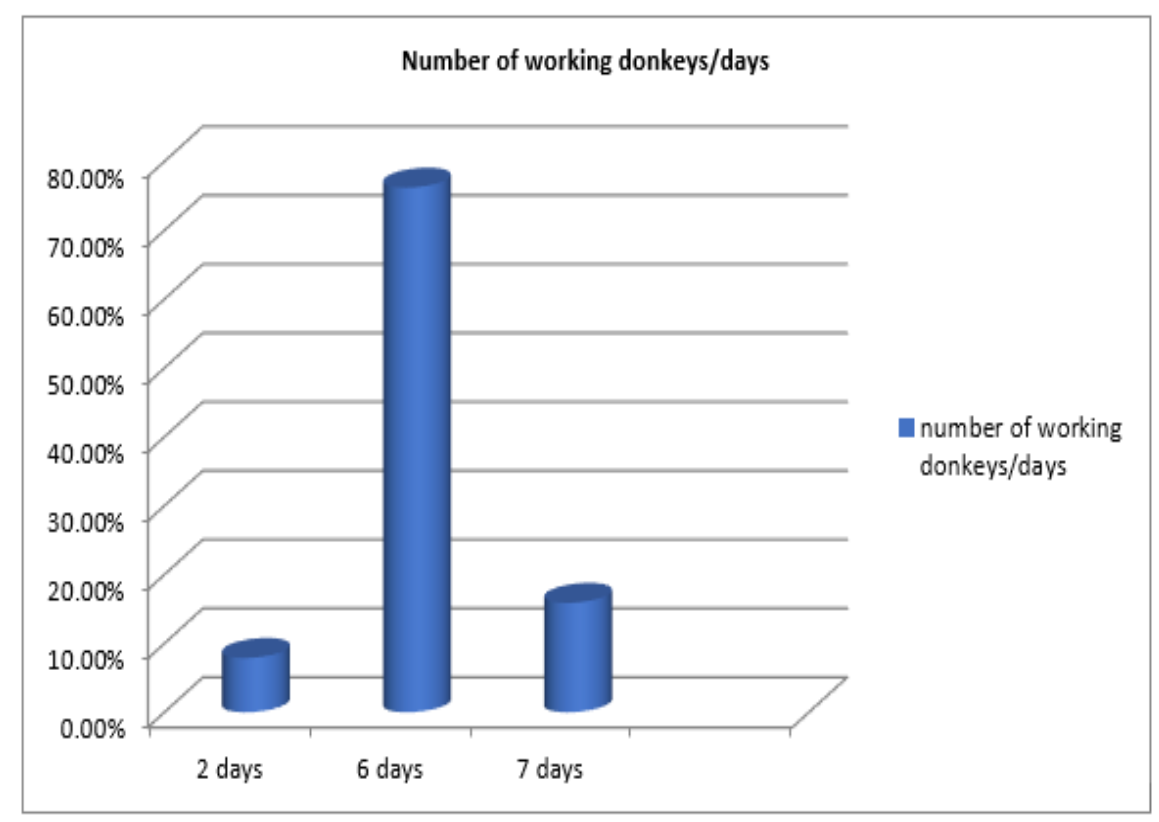

Figure 1: Number of working donkeys per day.

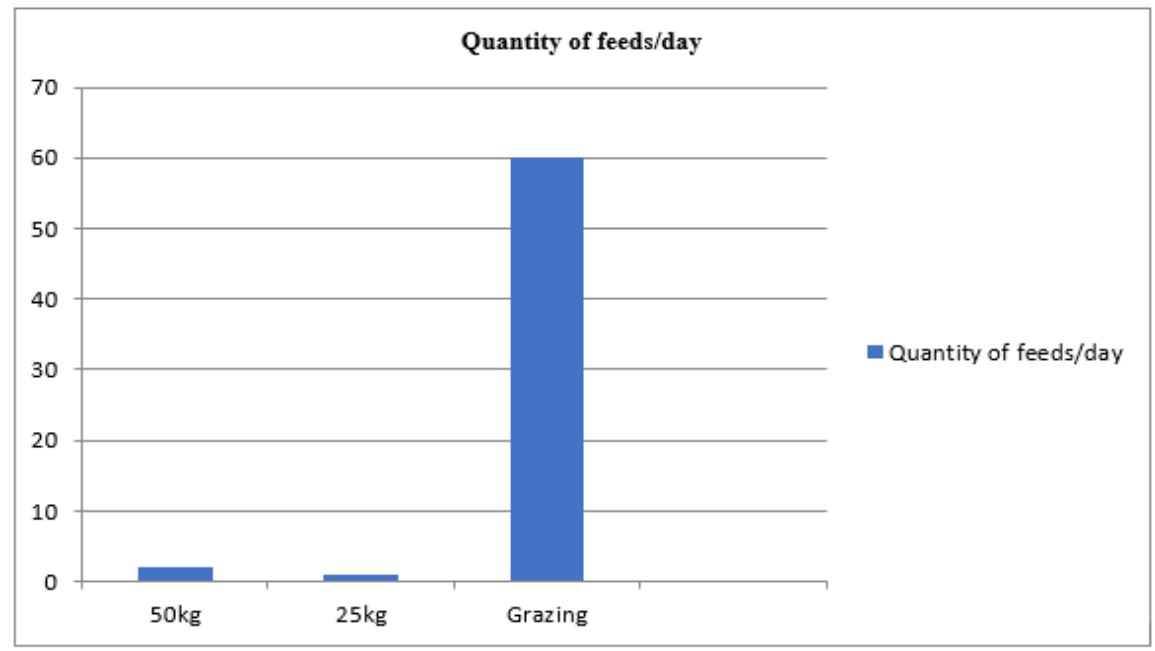

Figure 2: Feeding of working donkeys per day.

most common feed, others feed their donkeys with maize straws. Some donkey owners said that they supplement their donkeys with carrots and leguminous plants like the cow peas remains

\section{Watering Frequency}

This study revealed that $90.5 \%$ of the respondents provided water to the donkeys once a day, $1.6 \%$ of the respondents provided water thrice a day during the working hours and $7.9 \%$ of the respondents do not provide water to the working donkeys and this occurs especially during the market days when the donkeys are hired. The donkeys were left to drink water from the river therefore the amount or quantity of water given to the donkeys was not well known by the donkey owners.

\section{Health Assessment}

This study showed that there were no donkeys having abnormal mucous membranes, abnormal buccal cavity, eye abnormalities and respiratory conditions. Most of the assessed donkeys had fairly normal oral health apart from few cases of tartar, plaques and erosions on the teeth. Most $(84.1 \%)$ of the working donkeys had fair body condition with a score of $3 / 5$ and $15.9 \%$ of the donkeys were in good body condition with a body score of $4 / 5$. This indicated that despite the donkey's feeding regime being poor, they were getting most of the nutrients from the grazing site and the little supplementation given to them after work in the evening.

In this study $93.7 \%$ of the working donkeys were male

Citation: Grace Atieno, Ngetich Wyckliff, Wahome Margaret Wambui, Chepkirui Evalyne Bett. An Insight on the Welfare of Working Donkeys in Njoro Community, Nakuru. Op Acc J Bio Sci \& Res 7(1)-2021. 
and they had skin lesions especially on the shoulder, the forelimbs and the rump lesions. The lesions were as a result of poor harnessing method and materials. The lesions on the forelimbs mostly were as a result of tightening one of the forelimbs with a rope since most donkey owners tied one of their donkeys under a tree when they are left to rest. The lesions on the rump were mostly inflicted by the donkey owners due to severe whipping of the donkey for it to increase its speed during work. The lesions were not fresh and most were healing and had formed scab.

Majority (93.7\%) of the observed donkeys in this study had hoof problems such as overgrowth and cracks which could be attributed to the nature of the tredding paths along the tarmac road. All of the respondents admitted that they had never attempted hoof trimming and even if they were to do it, they would not because of fear of being kicked by the donkeys or causing injuries to the hooves. All observed donkeys were active and alert.

\section{Veterinary Services}

In this study $58.7 \%$ of the respondents had their donkeys vaccinated during some rabies vaccination campaign and $23.8 \%$ of the respondents deworm their donkey at least once a year. On the other hand, $63.5 \%$ of the respondents would seek veterinary services when their donkeys become sick while $36.5 \%$ of the respondents however admitted that they do not seek veterinary services since their donkeys rarely get ill and if they do so they naturally get healed.

\section{Harnessing Materials}

This study revealed that the harnessing materials and methods of the donkeys were poor. The type of harnessing materials used was a suck and a rope inserted in a hose pipe. Others just used rope only without inserting it in a hose pipe for protection. One donkey owner who owned one donkey had cloth rags filled in a suck to protect donkey from being injured with firewood. This therefore indicates that almost all of the donkey owners lacked proper harnessing materials and padding materials to offer proper protection against harnessing wounds.

\section{Sheltering}

According to this study, all the donkey owners provided shelter for their donkeys at night. However, most (87.3\%) of the donkey owners mixed the donkeys and the other animals at night in a resting yard.

\section{Resting of Donkeys}

In this study, donkeys were rested especially at noon and in the afternoon in shades when the temperatures were high.

\section{Breeding}

This was most neglected welfare issue in Njoro community. In this study, $93.7 \%$ of the interviewed donkey owners had male donkeys and $6.3 \%$ had female donkeys. This showed that most donkeys in Njoro community were male and those that owned female donkeys were in the group of those individuals who had more than two donkeys. They however claimed that they rarely use the female donkeys and thus they usually leave them at home. They also said that if they were to use the female donkey, it's either one donkey is sick, tired or has died. The reason why they didn't like the female donkey is that they think it is a waste since the donkey might end up reproducing when they are mixed together reducing the work power. They also claim that the female donkeys might not allow the male donkeys to work properly. Others also claimed that the female donkeys tend to tire faster than the male donkeys.

\section{Donkey Slaughter}

When interviewed on donkey slaughter, most of the donkey owners were against the donkey slaughter. They complained that when the donkey slaughter started most of their colleagues lost their donkeys to theft. They also reported that the only meat that they know is the meat of the cattle, sheep and goat and that those that have eaten the donkey meat are either not in their senses or if they have eaten it they did it unintentionally. Others claimed that if the slaughter continues, the donkey population will be at risk and this will affect them since most of them earn their living through the aid of the donkeys.

\section{Discussion}

Most of the respondents were married males thus making this business of using working donkey as male business. This male domination could be because of the job involves handling heavy things such as goods and water that women can hardly handle. The findings also showed that $96.8 \%$ of the respondents were literate. This showed that despite the donkey business being good, the donkey handlers had a little knowledge on how to interact and associate with the animals for a better business. According to and Hemsworth (1990), education has influence on perception and involvement, particularly in decision making and monitoring of activities regarding resource use. In this study $84.1 \%$ of the respondents owned 2 donkeys and this showed that the donkeys could be used even when they are sick or tired and this therefore indicates poor welfare

Citation: Grace Atieno, Ngetich Wyckliff, Wahome Margaret Wambui, Chepkirui Evalyne Bett. An Insight on the Welfare of Working Donkeys in Njoro Community, Nakuru. Op Acc J Bio Sci \& Res 7(1)-2021. 
status. This is different to what was reported by of $75 \%$ of the responding donkey owners owning only one working donkey and $25 \%$ of them owning more than one.

The study also revealed that $76.2 \%$ of working donkeys work 6 days in a week to transport water to hotels, homesteads and construction sites and $79.4 \%$ of the working donkeys work from morning to noon to transport water to hotels. This indicated that as much as donkey business was concerned, the donkey owners/ handlers spared some time and a day in a week for the donkeys to rest thus indicating good welfare. This finding however contrast with a study carried out by Kamonzo, [6], that nearly half of the urban/ peri-urban donkeys work for 7 days per week and thus they have less time to rest. Some (7.9\%) of the working donkeys were hired mostly during the market days especially on Wednesdays and Saturdays to transport goods to the market during the morning hours. According to this study, $7.9 \%$ of the working donkeys were used to do household chores like collecting firewood by women. Others however used the donkeys once in a while to move students who were moving their furniture from one rental to other and to fetch drinking water for animals in a large farm.

According to this study, $95.2 \%$ of the owners interviewed admitted that they leave the donkeys to graze on their own on dry grass after work. Besides grazing, $3.2 \%$ and $1.6 \%$ of the interviewed owners provide the donkeys 1 suck and $1 / 2$ suck of dry grass and maize straw respectively in the evening after work. However, $12.7 \%$ would get other supplements such as carrots or leguminous plants like cow peas. These therefore indicate poor feeding regime since the donkeys are not supplemented with extra requirements like minerals and salts. This finding is not in line with a finding that was documented by Pearson et al. [7] that donkeys should be provided daily with straws or hay equal to $5 \%$ of its body weight, even though it may only eat half of this. According to Aganga et al. [8], when the animals are expected to produce extra work or when the grazing range has been depleted, supplementary feeding may be required. In addition to that, the findings also showed that the donkey owners and handlers were not interested in the consumption intake capacity of the donkeys thus poor feeding welfare.

Water is vital for donkeys and over $60 \%$ of an equines body consists of water Duncunson [9]. Even though donkeys are more thirst tolerant than horses and will maintain their appetites in conditions of water deprivation, they have the same water requirements as horses Duncanson [9]. In this study, $90.5 \%$ of the respondents provided water to the donkeys once a day, $1.6 \%$ of the respondents provided water thrice a day during the working hours and $7.9 \%$ of the respondent do not provide water to the donkeys and this occurs especially during the market days when the donkeys are hired. This therefore indicates poor welfare since the donkeys should always have access to clean water.

About $58.7 \%$ of the respondents had their donkeys vaccinated during some rabies vaccination campaign and $23.8 \%$ of the respondents deworm their donkey at least once a year. On the other hand, $63.5 \%$ of the respondents would seek veterinary services when their donkeys become sick while $36.5 \%$ of the respondents however admitted that they do not seek veterinary services since their donkeys rarely get ill and if they do so they naturally get healed. This indicates that the donkey's health status is not a priority for as long as they can provide power and work to their owners. This however contrast with a study carried out in Ethiopia by Niraj [10] on donkey welfare assessment where $31.6 \%$ of the diseased donkeys were taken to veterinary clinics, $10.5 \%$ were treated traditionally and $57.9 \%$ did not get any help from their owners and were forced to work regardless of the disease.

Based on the findings of the study, all the donkey owners provided shelter for their donkeys at night. However, most $(87.3 \%)$ of the donkey owners mix the donkeys and the other animals at night in a resting yard. The donkeys were also being rested especially at noon and in the afternoon when the temperatures were high. All the donkeys observed for this study were alert and active thus indicating good welfare.

On health assessment, the study showed that there were no donkeys having abnormal mucous membranes, abnormal buccal cavity, eye abnormalities and respiratory conditions. Most of the assessed donkeys had fairly normal oral health apart from few cases of tartar, plaques and erosions on the teeth. Most (84.1\%) of the working donkeys had fair body condition with a score of $3 / 5$ and $15.9 \%$ of the donkeys were in good body condition with a body score of 4/5. This indicated that despite the donkey's feeding regime being poor, they were getting most of the nutrients from the grazing site and the little supplementation given to them after work in the evening.

In this study $93.7 \%$ of the working donkeys were male and they had skin lesions especially on the shoulder, the forelimbs and the rump lesions. The lesions were as a result of poor harnessing method and materials. The lesions on the forelimbs mostly were as a result of tightening one of the forelimb with a rope since most donkey owners tied one of their donkey under a tree when they are left to rest. The lesions on the rump were mostly inflicted by the

Citation: Grace Atieno, Ngetich Wyckliff, Wahome Margaret Wambui, Chepkirui Evalyne Bett. An Insight on the Welfare of Working Donkeys in Njoro Community, Nakuru. Op Acc J Bio Sci \& Res 7(1)-2021. 
donkey owners due to severe whipping of the donkey for it to increase its speed during work. In a similar study by Niraj [10], the greater distribution of wounds was found at the withers and back region (14.3\%) and under the tail (7.7\%). These findings therefore showed that most donkey owners had no proper harnessing materials and their handling techniques was also poor. Most (93.7\%) of the observed donkeys in this study had hoof problems such as overgrowth and cracks which could be attributed to the nature of the tredding paths along the tarmac road. All of the respondents admitted that they had never attempted hoof trimming and even if they were to do it, they would not because of fear of being kicked by the donkeys or causing injuries to the hooves.

According to the study, $93.7 \%$ of the interviewed donkey owners had male donkeys and $6.3 \%$ had female donkeys. This showed that most donkeys in Njoro community were male and those that owned female donkeys were in the group of those individuals who had more than two donkeys. They however claimed that they rarely use the female donkeys and thus they usually leave them at home. They also said that if they were to use the female donkey, it's either one donkey is sick, tired or has died. The reason why they didn't like the female donkey is that they think it is a waste since the donkey might end up reproducing when they are mixed together reducing the work power. They also claim that the female donkeys might not allow the male donkeys to work properly. Others also claimed that the female donkeys tend to tire faster than the male donkeys.

Generally harnessing method of the donkeys was poor. The type of harnessing materials used was a suck and a rope inserted in a hose pipe. Others just used rope only without inserting it in a hose pipe for protection. One donkey owner who owned one donkey had cloth rags filled in a suck to protect donkey from being injured with firewood. Due to this poor harnessing technique most of the donkeys had shoulder wounds especially those donkeys that were used for pulling carts during water transportation. This therefore indicates that almost all of the donkey owners lacked proper harnessing materials and padding materials to offer proper protection against harnessing wounds.

When interviewed on donkey slaughter, most of the donkey owners were against the donkey slaughter. They complained that when the donkey slaughter started most of their colleagues lost their donkeys to theft. They also reported that the only meat that they know is the meat of the cattle, sheep and goat and that those that have eaten the donkey meat are either not in their senses or if they have eaten it they did it unintentionally. Others claimed that if the slaughter continues, the donkey population will be at risk and this will affect them since most of them earn their living through the aid of the donkeys. These findings are in line with the findings documented by Maichomo et al. [11] that there was an increasing trend in the number of donkeys slaughtered in subsequent years and thus contributing to the reduction in the donkey population to the extent of being extinct by 2022. According to Maichomo et al. [11], demand for donkeys far outweighed the supply thus cases of donkey theft.

\section{Conclusion}

The donkey welfare status among working donkeys in Njoro community was poor which can be contributed by poor harnessing techniques and management practices such as feeding and disease control [12].

\section{Recommendations}

From the findings of this study, the following recommendations can be drawn; the donkey owners and users should be sensitized on donkey welfare (the five freedoms) and proper harnessing, they can be trained on how to make better harness using locally available materials, the importance of donkeys as a source of livelihood and the need to ensure their welfare.

\section{Conflict of Interest}

The authors have none to declare

\section{References}

1. Peterson L Anna (1999) Recent studies and issues in animal welfare. Journal of Agricultural and Environmental Ethics 12: 215-222

2. Broom M Donald (2005) Animal welfare science. Rassegna di Diritto Legislazione e Medicina Legale Veterinaria 4: 9-29

3. Valette Dolphine (2015) Invisible workers: The Economic Contributions of Working Donkeys, Horse and Mules to Livelihoods. The Brook East Africa 4-40.

4. Herago Tamirat, Mulisa Megersa Kebeta, Ayalew Niguse Alemu, Teka Fegera (2015) Assessment on working donkey welfare issues in Wolaita SoddoZuria District, Southern Ethiopia. Global Veterinarian 14(6): 867-875.

5. Kenya Population and Housing Census (2019) Counting our people for sustainable development and devolution of services. Kenya National Bureau of Statistics

6. Kamonzo JK, Titus KI, Jemimah OA (2017) The Use of Physical Animal Welfare Indicators: A case for Working Donkeys in Rural and Urban/Peri- Urban Areas of Mwingi Central Sub County-Kitui County, Kenya. International Journal of Education and Research 4: 1- 20.

7. Pearson RA, Alemayehu M, Tesfaye A, Allan EF, Smith D, et al. (2001) Use and management of donkeys in peri-urban areas of Ethiopia, Phase 1. University of Edinburgh and Ethiopian agricultural research organization collaborative project, Center for Tropical Veterinary Medicine, Draught animal power technical report 5 .

Citation: Grace Atieno, Ngetich Wyckliff, Wahome Margaret Wambui, Chepkirui Evalyne Bett. An Insight on the Welfare of Working Donkeys in Njoro Community, Nakuru. Op Acc J Bio Sci \& Res 7(1)-2021. 
8. Aganga AA, Letso M, Aganga AO (2000) Feeding donkeys. Journal of livestock research for rural development, Volume $12(2)$.

9. Duncanson (2010) A guide of improving the welfare of working animals.

10. Niraj K (2014) Welfare assessment of working donkeys in Mikelle City, Ethiopia. Journal of the Global veterinarian 12 (3): 314-319.
11. Maichomo MW, Karanja Lumumba T, Olum MO, Magero J, Okech T (2019) The status of donkey slaughter in Kenya and its implication on community livelihoods. The Brooke East Africa.

12. Barnett JL, Hemsworth PH (1990) The validity of physiological and behavioral measures of animal welfare. Journal of Applied Animal Behavior Science 25: 177-187.

\section{*Corresponding author: Ngetich Wyckliff, Email: wyckymos@gmail.com}

Next Submission with BGSR follows:

- Rapid Peer Review

- Reprints for Original Copy

- E-Prints Availability

- Below URL for auxiliary Submission Link: https://biogenericpublishers.com/submit-manuscript/ 